\title{
MONOCLONAL ANTIBODIES TO CHOLINE ACETYLTRANSFERASE: PRODUCTION, SPECIFICITY, AND IMMUNOHISTOCHEMISTRY ${ }^{1}$
}

\author{
A. I. Levey,* D. M. Armstrong, $\ddagger$ S. F. Atweh,§ R. D. Terry, $\ddagger$ and B. H. Wainer* $\|^{2}$ \\ Departments of *Pathology, \|Pediatrics, and \$Neurology, University of Chicago, Chicago, Illinois 60637 and $\ddagger$ Department of \\ Pathology, Albert Einstein College of Medicine, Bronx, New York 10461
}

Received March 1, 1982; Revised August 3, 1982; Accepted August 3, 1982

\begin{abstract}
Immunohistochemical localization of choline acetyltransferase (ChAT) in cholinergic neurons has been difficult to achieve because of problems encountered in producing specific antisera. Here we describe the production and characterization of several distinct monoclonal antibodies to ChAT. Each of the monoclonal antibodies exhibits one of three general patterns of cross-species reactions; one pattern shows reactivity limited mainly to bovine ChAT, a second pattern shows reactivity only to ChAT from higher mammals including humans, and the third pattern shows reactivity to ChAT from all mammals tested. The antibodies bound specifically to two closely related bovine proteins of 68,000 and 70,000 daltons using the Western blotting technique. One of the antibodies was used to localize immunohistochemically known cholinergic structures in the rat brain, including motor neurons, basal forebrain neurons, and neostriatal neurons.
\end{abstract}

Cholinergic neurons are responsible for many important neuronal processes, including some aspects of learning and memory (Drachman, 1981). Certain neurologic diseases such as Alzheimer's disease and Huntington's chorea are thought to result from a selective dysfunction of cholinergic innervation in the cortex and striatum, respectively (Terry and Davies, 1980; Aquilonius et al., 1975). Because a detailed knowledge of cholinergic neuroanatomy is not presently available, the role of these neurons in health and disease is not well understood. Most mapping studies have employed histochemical techniques for acetylcholinesterase (AChE), a marker which is not specific for cholinergic neurons. More recent studies have employed polyclonal antisera to choline acetyltransferase (ChAT, E.C. 2.3.1.6), this enzyme being the most reliable marker for cholinergic neurons (Kimura et al., 1981; Kan et al., 1980). These latter studies have been criticized because of the questionable specificity of the antisera employed (Rossier, 1975, 1981). Recently, we have reported the first successful production of monoclonal antibodies against ChAT (Levey et al., 1981).

\footnotetext{
'This work was supported in part by United States Public Health Service Research Grants HD-04583 and NS-17661 and the Whitehall Foundation, Inc. (B. H. W., P.I.), United States Public Health Service Research Grant NS-02255 and a grant from the McKnight Foundation (R. D. T., P.I.), and a Francis L. Lederer Foundation Fellowship (A. I. L., recipient).

${ }^{2}$ To whom correspondence should be addressed at Department of Pathology, University of Chicago, 950 E. 59th Street, Box 228, Chicago, IL 60637.
}

These antibodies, $\mathrm{AB} 1$ and $\mathrm{AB} 4$, were found to have reactivity limited mainly to bovine ChAT (Levey and Wainer, 1982). Antibodies with wider cross-species reactivities would be useful for a variety of studies of cholincrgic neurons. For example, detailed neuroanatomical mapping studies are best performed in rodents, while investigations into the role of cholinergic neurons in pathological conditions such as Alzheimer's disease necessitate antibodies reactive with human ChAT. Therefore, we performed a second cell fusion experiment and here describe the production and characterization of monoclonal antibodies reactive with ChAT from several mammalian species. Further studies are presented which confirm the specificity of the monoclonal antibodies and demonstrate for the first time their use in localizing cholinergic structures in the rat brain.

\section{Materials and Methods}

Partial purification of ChAT and immunizations. ChAT was partially purified from bovine caudate and rat brains according to the method of Ryan and McClure (1979) and as described earlier (Levey et al., 1981). The procedure included homogenization of tissue and solubilization of enzyme, fractionation under acidic conditions, 30 to $60 \%$ ammonium sulfate fractionation, and CMSephadex chromatography. After ion-exchange chromatography we achieved up to a 200 -fold purification with a $50 \%$ yield and a specific activity of $0.20 \mu \mathrm{mol} / \mathrm{min} / \mathrm{mg}$ of protein. A Lewis rat was immunized by intraperitoneal injection of $3 \mathrm{mg}$ of ion-exchange-purified bovine ChAT 
absorbed into the alum particulate phase from $1 \mathrm{ml}$ of Maalox. For the primary immunization, the rat also received $1 \mathrm{ml}$ of pertussis vaccine intramuscularly. Additional immunizations were given at 1-month intervals employing identical doses of ChAT but without pertussis. The antiserum was shown to have anti-bovine ChAT antibody activity using an immunoassay described previously (Levey et al., 1981). Since the purpose was to generate monoclonal antibodies with wide cross-species reactivities, the antiserum also was tested and found to be highly cross-reactive with rat enzyme. In order to stimulate lymphoid cells producing cross-reactive antibodies, the final immunization preparation contained approximately $3 \mathrm{mg}$ each of rat and bovine ChAT and was given intravenously.

Production of monoclonal antibodies. Spleen cells from the immune rat (no. 11) were removed 3 days after the final injection and fused with mouse myeloma cell line Sp2/0 using polyethylene glycol according to published procedures (McKearn, 1980; Levey et al., 1981). The advantages of using the Sp2/0 cell line are that it is nonsecreting, it grows rapidly, and it fuses very efficiently. The cells were dispensed into 576 wells on $96-$ well Costar plates $\left(3.0 \times 10^{5}\right.$ cells/well) and were cultured selectively in medium containing hypoxanthine/aminopterin/thymidine. Following 8 to 10 days, $100-\mu$ l samples were taken from each of the wells.

A co-precipitation antigen binding assay was used to detect antibodies reactive with ChAT. Briefly, mixtures of rat and bovine ChAT (previously adjusted to equivalent amounts of enzyme activity) were incubated with samples of hybridoma cultures for 4 to $5 \mathrm{hr}$ at $4^{\circ} \mathrm{C}$ in microtiter plate wells (final volume, $250 \mu \mathrm{l}$ ). Goat antirat immunoglobulin then was added, the plates were incubated overnight at $4^{\circ} \mathrm{C}$, and then centrifuged at 1000 $\times g$ for $15 \mathrm{~min}$. Immunoprecipitates were washed once, recentrifuged, resuspended in $25 \mu \mathrm{l}$ of $10 \mathrm{~mm}$ citrate/ phosphate buffer containing $0.1 \mathrm{mM} \mathrm{EU}$ 'TA and $7 \%$ glycerol (CPEG buffer), and assayed for ChAT activity. This assay previously was shown to be specific for anti-ChAT antibodies (Levey et al., 1981; Levey and Wainer, 1982). ChAT activity, expressed as DPM $\left[{ }^{3} \mathrm{H}\right]$ acetylcholine synthesized in $40 \mathrm{~min}$ at $37^{\circ} \mathrm{C}$, was assayed using the radiochemical method of Fonnum (1975).

Cloning and expansion of hybridomas. Monoclonal hybridoma cell lines were obtained by several clonings at limiting dilution. Anti-ChAT antibody-secreting hybridomas were diluted with culture medium (Dulbecco's modified medium $/ 20 \%$ agamma horse serum) and $100-\mu 1$ aliquots (containing on the average one cell) were pipetted into 96-well Costar plates containing $100 \mu \mathrm{l}$ of culture medium previously conditioned with Lewis rat thymocytes $\left(10^{7}\right.$ cells $\left./ \mathrm{ml}\right)$. Cloned cells were expanded and passaged in either cultures or ascites fluids of nude mice. All cell lines were stored for future use by freezing in liquid nitrogen at $2 \times 10^{6}$ cells $/ \mathrm{ml}$ in culture medium plus $10 \%$ dimethyl sulfoxide.

Monoclonal antibodies were harvested from clarified cultures, partially purified by $50 \%$ ammonium sulfate fractionation, and then resuspended in one-tenth the original volume in CPEG buffer. Antibodies also were harvested from the ascites fluids of nude mice. Further purification of antibodies was achieved by affinity chro- matography using immobilized goat anti-rat IgG and elution at $\mathrm{pH} 2.8$.

Western blotting studies. Sodium dodecyl sulfatepolyacrylamide gel electrophoresis (SDS-PAGE) was performed in $10 \%$ polyacrylamide slab gels $(16 \mathrm{~cm} \times 18$ $\mathrm{cm} \times 0.75 \mathrm{~mm}$ ) using the discontinuous buffer system of Laemmli (1970). Proteins were visualized in the gels using a sensitive silver stain (Merril et al., 1981), and molecular weights were estimated with the low molecular weight standards from Bio-Rad.

Either a crude extract of bovine brain $(0.001 \mu \mathrm{mol} /$ $\mathrm{min} / \mathrm{mg})$ or partially purified bovine ChAT $(0.20 \mu \mathrm{mol} /$ $\mathrm{min} / \mathrm{mg}$ ) was applied to the gels, using the equivalent of approximately 30 to $50 \mu \mathrm{g}$ of protein/lane. Following electrophoresis, the slab gels (minus the stacking gels), four pieces of coarse grade Whatman filter paper, and one piece of nitrocellulose paper $(0.45 \mu \mathrm{m}$ pore size, Schliecher and Shuell) cut slightly larger than the gel were immersed in $0.22 \mathrm{M}$ sodium phosphate buffer, $\mathrm{pH}$ 7.4 , for $20 \mathrm{~min}$. Proteins were transferred from the gel to the nitrocellulose sheet by suction filtration. This technique was modified from electrophoretic procedures used for protein transfer (Burnette, 1981) and DNA blotting techniques. The physical assembly used for blotting consisted of the following. The nitrocellulose sheet was laid on two sheets of filter paper on a slab gel dryer. The gel was carefully placed on top of the nitrocellulose paper and covered with the other two sheets of filter paper. Phosphate buffer was poured over the sandwich, and suction was applied for $4 \mathrm{hr}$ with rewetting of the sandwich every hour. Although transfer was not quantitative, most proteins under 100,000 daltons were visible on protein-stained blots $(0.1 \%$ amido black $/ 45 \%$ methanol $/ 10 \%$ acetic acid and destained with $90 \%$ methanol $/ 2 \%$ acetic acid).

Following the protein transfer, the remaining protein binding sites on the nitrocellulose sheet were saturated by immersing the blots in medium I ( $1 \%$ gelatin/ $150 \mathrm{mM}$ $\mathrm{NaCl} / 50 \mathrm{~mm}$ Tris-HCl, $\mathrm{pH}$ 7.4) for about $1 \mathrm{hr}$ at room temperature. This treatment prevented nonspecific binding of antibodies to the blots. Strips cut from the blot (approximately $5 \mathrm{~mm}$ wide) then were incubated overnight with $100 \mu \mathrm{g}$ of either rat IgG or affinity-purified monoclonal antibody diluted to $3.0 \mathrm{ml}$ in $5 \%$ normal rabbit serum $/ 0.25 \%$ Triton $\mathrm{X}-100 / 50 \mathrm{~mm}$ Tris, $\mathrm{pH} 7.6$. Antibodies then were localized using the indirect peroxidase-antiperoxidase (PAP) method (Sternberger, 1979), as used for immunohistochemistry. Blots were rinsed with Tris buffer and incubated for $1 \mathrm{hr}$ with rabbit antirat IgG diluted $1 / 100$ in Tris buffer containing $10 \%$ normal rabbit serum. Blots were rinsed again and incubated for another hour in rat PAP diluted $1 / 100$ in 10\% normal rabbit serum. After washing, bound antibodies were stained with $0.05 \% 3$-3'-diaminobenzidine (DAB) $/ 0.005 \%$ hydrogen peroxide $/ 50 \mathrm{~mm}$ Tris- $\mathrm{HCl}, \mathrm{pH}$ 7.6. The blots were rinsed in distilled water to terminate the reaction and then air dried. Because the gels expand after protein staining, molecular weight sizing on the blots was facilitated by electrophoresing and blotting bovine serum albumin (BSA; 68,000 daltons). BSA then was immunostained using rat anti-BSA sera (kindly provided by Dr. Barbara Peri, University of Chicago).

Immunohistochemical localization of ChAT in rat 
brain. Male Sprague-Dawley rats (120 to $160 \mathrm{gm}$ ) were anesthetized with pentobarbital $(50 \mathrm{mg} / \mathrm{kg})$ and perfused through the ascending aorta with $400 \mathrm{ml}$ of $4 \%$ paraformaldehyde and $0.1 \%$ glutaraldehyde in $0.1 \mathrm{M}$ phosphate buffer at $\mathrm{pH}$ 7.4. The brains were removed and coronal slices were made with a razor blade throughout the entire rostrocaudal extent of the brain and subsequently were placed in the same fixative for an additional $30 \mathrm{~min}$. The tissue then was sectioned on a vibrating microtome (Vibratome) at a thickness of 30 to $35 \mu \mathrm{m}$. The sections were
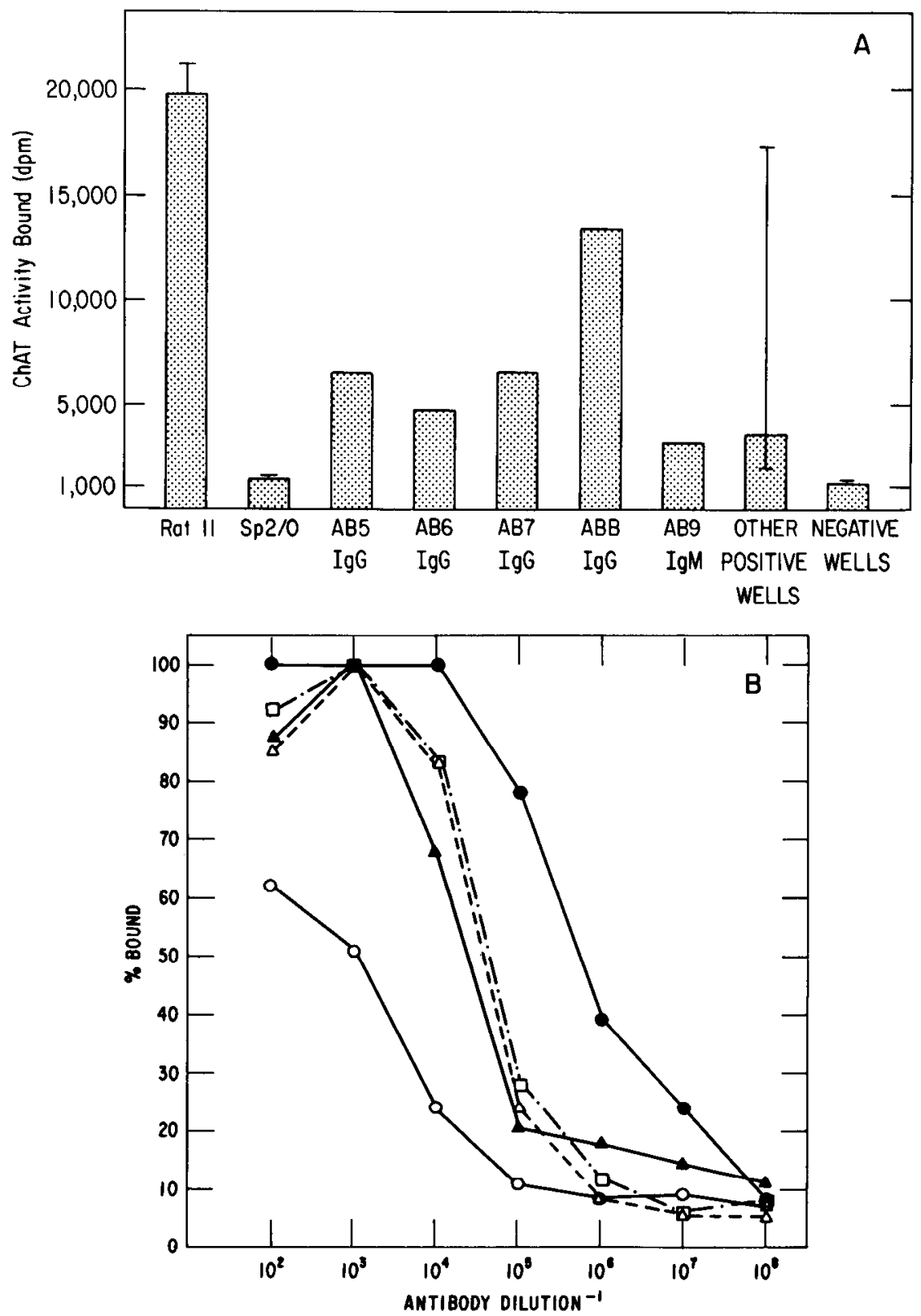

Figure 1. A, Results of cell fusion experiment with rat no. 11 spleen cells and mouse myeloma cell line Sp2/0. Anti-ChAT antibody activity in the samples was determined using the immunoassay described in the text. Approximately $0.06 \mathrm{nmol} / \mathrm{min}$ of enzyme activity $(0.03 \mathrm{nmol} / \mathrm{min}$ each of rat and bovine ChAT) was incubated with rat no. 11 immune serum (1/400 final dilution), Sp2/0 myeloma culture supernatant (1/2.5 final dilution), or hybridoma culture supernatant (1/2.5 final dilution). Normal rat serum was added to each sample at a final dilution of $1 / 100$, and goat anti-rat immunoglobulin was added to a final dilution of $1 /$ 10. Results are plotted as the ChAT activity ( $\mathrm{dPM}\left[{ }^{3} \mathrm{H}\right]$ acetylcholine formed in $40 \mathrm{~min}$ at $37^{\circ} \mathrm{C}$ ) precipitated in the presence of either immune rat serum, hybridoma supernatants, or Sp2/0 culture supernatant. The bars represent standard deviation, except for other positive wells where the bar represents the range around the mean anti-ChAT activity of the 47 positive wells. No bars are shown for AB5 to AB9; due to small sample volumes, only single determinations were performed for initial screening of culture supernatants.

$B$, Bovine ChAT binding curve for anti-ChAT monoclonal antibodies. The antibodies were diluted from the ascites fluids of nude mice. The percentage bound was calculated from ChAT activity recovered in immunoprecipitates (corrected for nonspecific trapping) divided by the total amount of enzyme activity added $(0.06 \mathrm{nmol} / \mathrm{min}$ of bovine ChAT). Nonspecific trapping of ChAT in Sp2/0 control immunoprecipitates was less than $5 \%$ of total ChAT activity. AB9, 一-; AB5, - $-; \mathrm{AB} 6,-\boldsymbol{\Lambda}-; \mathrm{AB}$, -.- $\square$ - - ; AB8, - - 
transferred to spot test plates (Fisher Co.) containing 0.1 M Tris, $0.15 \mathrm{M} \mathrm{NaCl} \mathrm{(pH} \mathrm{7.4)} \mathrm{in} \mathrm{preparation} \mathrm{for} \mathrm{the} \mathrm{PAP}$ labeling procedure, which consisted of the following series of steps: $(a)$ overnight incubation with a $1 / 40$ dilution of ammonium sulfate-fractionated culture supernatant of hybridoma AB8 or control culture supernatants of Sp2/ 0 myeloma cells with rat IgG $(1 \mathrm{mg} / \mathrm{ml}$ added); $(b) 30$ min of incubation with goat anti-rat IgG diluted $1 / 40$ with $1 \%$ goat serum in $0.1 \mathrm{M}$ Tris/saline; (c) $30 \mathrm{~min}$ of incubation with rat PAP complex diluted $1 / 40$ with $1 \%$ goat serum in Tris/saline. The sections then were reacted for 8 min with a $0.05 \%$ solution of $3-3^{\prime}$-diaminobenzidine (DAB) in the presence of $0.01 \%$ hydrogen peroxide to yield a brown reaction product. Following each incubation the sections were rinsed twice in Tris/saline except after the $\mathrm{DAB}$ reaction when the sections were washed in distilled water. All incubations were carried out at room temperature. The sections were free-floating and continuously agitated on a Thomas rotator through all incubations and washes. Sections were mounted on albumin-coated slides, dehydrated, covered with glass coverslips, and examined on a Zeiss microscope using Nomarski optics.

\section{Results}

Production and characterization of the monoclonal antibodies. The immune serum from rat no. 11 was tested for antibody activity in the co-precipitation assay, and active enzyme was recovered in the immunoprecipitates. Control experiments employed pre-immune (normal) rat serum and resulted in nonspecific precipitation of less than $1 \%$ of the ChAT activity bound by immune serum. Mixing of the immune serum and bovine ChAT overnight at $4^{\circ} \mathrm{C}$ did not result in any significant inhibition of enzyme activity compared to normal rat serum. Therefore, the hybridoma screening assay was designed to select those populations of antibodies capable of binding active ChAT, such that only the bound active enzyme recovered in the immunoprecipitates was monitored. The results of the initial screening assay from the cell fusion experiment are shown in Figure $1 A$. All assays included a positive control using the donor rat's (no. 11) immune serum as well as a negative control using $\mathrm{Sp} 2 / 0$ culture media to determine nonspecific trapping of ChAT in the immunoprecipitates. All of the hybridoma culture wells exhibited hybridoma proliferation and $9 \%$ (52 wells) were posilive for anti-ChAT activity. Five stable hybridomas (AB5 to AB9) were isolated and expanded following cloning. Cells in the remaining 47 positive wells were frozen. The isotypes of monoclonal antibodies AB5 to AB9 were determined by immunodiffusion using classspecific antisera and are also shown in Figure 1A. The antigen binding curves for the monoclonal antibodies harvested as nude mice ascites are shown in Figure $1 B$. Three of the five antibodies (AB5, AB6, and AB7) bound $50 \%$ of the antigen added at dilutions up to $1 / 50,000$ and AB8 bound comparable amounts at a dilution of $1 / 750$,000 . These binding curves probably reflect both differences in the amount of antibody produced by the individual hybridomas and/or differences in their affinities for ChAT.

Although the monoclonal antibodies were selected for their ability to bind active enzyme, it was possible that antibody binding might result in partial inhibition of enzyme activity. This possibility was tested by mixing bovine ChAT with each of the monoclonal antibodies overnight at $4^{\circ} \mathrm{C}$. None of the antibodies were found to result in any significant inhibition of ChAT activity.

Cross-species reactivities of monoclonal antibodies to ChAT. The cross-species reactivities of monoclonal antibodies $\mathrm{AB} 5$ to $\mathrm{AB} 9$ were determined using the co-precipitation antigen binding assay described above. ChAT was solubilized from the brains of the species listed in Table I and diluted with CPEG to approximately equivalent amounts of enzyme activity. The dilutions of each antibody (prepared from 50\% ammonium sulfate fractionation of hybridoma culture supernatants) were determined such that 40 to $50 \%$ of bovine ChAT added in the immunoassay was bound (except AB9 which bound only $17 \%$ at the lowest dilution tested). Measurements of ChAT activity in the immunoprecipitates showed that all antibodies bound significant amounts of bovine, human, sheep, and cat enzymes. In addition, one antibody, $\mathrm{AB} 8$, reacted equally well with ChA'T from all mammalian species tested and also bound to avian ChAT. Previously, we isolated two monoclonal antibodies $(A B 1$ and $\mathrm{AB} 4)$ reactive with bovine ChAT from the first cell fusion experiment (Levey et al., 1981). Both AB1 and AB4 also were found to react weakly with human and ovine ChAT but with no other species tested (Levey and Wainer, 1982).

\section{TABLE I}

Cross-species reactivities of anti-ChAT monoclonal antibodies

ChAT was solubilized from each of the sources as described previously (Levey and Wainer, 1982). Approximately $0.05 \mathrm{nmol} / \mathrm{min}$ of enzyme activity from each species was incubated with a dilution of one of the monoclonal antibodies or $\mathrm{Sp} 2 / 0$ culture supernatant in the immunoassay described in the text and in the legend to Figure 1. The antibodies and $\mathrm{Sp} 2 / 0$ were concentrated 10 -fold by $50 \%$ ammonium sulfate fractionation of culture supernatants. Antibody dilutions were determined such that 40 to $50 \%$ of bovine ChAT was bound, in order to utilize the linear portion of the antigen binding curve. The final dilution of each antibody was as follows: Sp2/0, AB5, AB6, AB7: 1/250; AB8: 1/ $1250 ; \Lambda B 9 ; 1 / 10$. The percentages bound were calculated from the equation:

\section{(ChAT activity in immunoprecipitates) \\ - (ChAT activity in Sp2/O immunoprecipitates) \\ Total ChAT activity}

The mean total ChAT activity for all species tested was $35,400 \pm 5500$ DPM $\left[{ }^{3} \mathrm{H}\right]$ acetylcholine formed in $40 \mathrm{~min}$ at $37^{\circ} \mathrm{C}$. The mean ChAT activity in $\mathrm{Sp} 2 / 0$ control immunoprecipitate for all species tested was $466 \pm 316 \mathrm{dpm}$.

\begin{tabular}{lccccc}
\hline \multirow{2}{*}{ Source of ChAT } & \multicolumn{5}{c}{ \% Bound by Monoclonal Antibody } \\
\cline { 2 - 6 } & AB5 & AB6 & AB7 & AB8 & AB9 \\
\hline Bovine caudate & 37 & 49 & 46 & 45 & 17 \\
Human caudate & 40 & 39 & 42 & 56 & 14 \\
Human placenta & 41 & 41 & 46 & 56 & 9 \\
Sheep caudate & 39 & 42 & 37 & 45 & 9 \\
Cat brain & 9 & 4 & 19 & 44 & 4 \\
Guinea pig brain & 0 & 0 & 0 & 52 & 0 \\
Rat brain & 0 & 0 & 0 & 40 & 0 \\
Mouse brain & 0 & 0 & 0 & 32 & 0 \\
Chicken brain & 0 & 0 & 0 & 9 & 0 \\
\hline
\end{tabular}




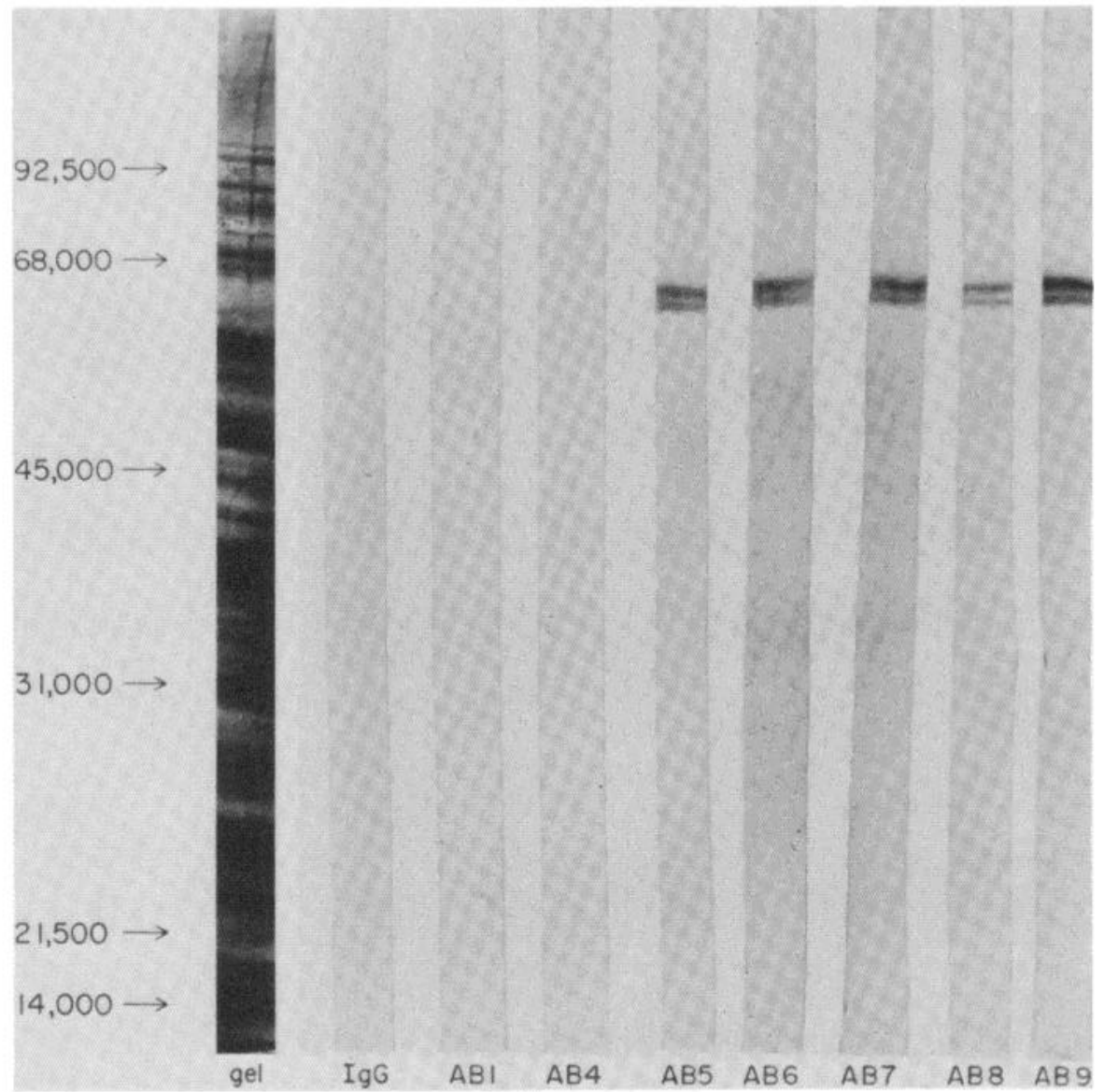

Figure 2. Binding of Anti-ChAT monoclonal antibodies to Western blots. Partially purified bovine ChAT was electrophoresed in a $10 \%$ SDS-polyacrylamide gel, blotted onto nitrocellulose paper, and then immunostained with monoclonal antibodies or a control employing rat IgG. On the left ( $\mathrm{gel}$ ) is a protein-stained lane in the gel before blotting, with molecular weights (arrows) determined in an adjacent lane in the same gel. The panel on the right shows the control blot stained with IgG and the experimental blots stained with monoclonal antibodies $\mathrm{AB} 1, \mathrm{AB} 4, \mathrm{AB} 5, \mathrm{AB} 6, \mathrm{AB} 7$, AB8, and AB9. The two immunostained protein bands are about 68,000 and 70,000 daltons (estimated by comparing to immunoblots of BSA, 68,000 daltons), but they appear lower than the 68,000 molecular weight marker because of expansion of the gel after protein staining.

All of the monoclonal antibodies also were tested for the capacity to inhibit enzyme activity in two crossreactive species. None of the antibodies inhibited enzyme activity when mixed with either human or rat ChAT.

Western blotting studies. Although monoclonal antibodies are highly specific reagents, it is possible that they will bind to molecules other than the one of interest if these other molecules contain shared antigenic determinants. The Western blotting technique was used to evaluate the specificity of the monoclonal antibodies reactive with ChAT. Partially purified bovine ChAT was electrophoresed using SDS-PAGE and then blotted onto nitrocellulose paper, as shown in Figure 2. Monoclonal antibodies AB5, AB6, AB7, AB8, and AB9 all bound to two bovine proteins on the nitrocellulose blots. By estimating from the mobility of the immunostained molecular weight marker BSA, the mobilities of the two antibodystained proteins correspond to about 68,000 and 70,000 daltons. None of the antibodies cross-reacted with any other protein bands seen in the gel. Monoclonal antibodies $\mathrm{AB} 1$ and $\mathrm{AB} 4$ did not bind to any of the proteins after SDS-denaturation, electrophoresis, and blotting, even though they both bind native bovine ChAT in the co-precipitation assay. The control blot employing an identical concentration of rat IgG did not result in any positive staining. A crude extract of bovine brain also was electrophoresed and stained using the Western blotting technique in order to see if the antibodies cross-react with any proteins from unfractionated brains. None of the antibodies stained any protein bands (not shown).

Immunohistochemical localization of ChAT in rat brain. Monoclonal antibody AB8, the one antibody reactive with all mammalian species of ChAT tested (see above), was used to localize ChAT immunoreactivity in the rat brain. Brain sections treated with rat IgG were used as a control and did not result in any positive staining (Fig. $3 B$ ). Sections treated with AB8 resulted in intense staining of ChAT immunoreactivity in the cyto- 

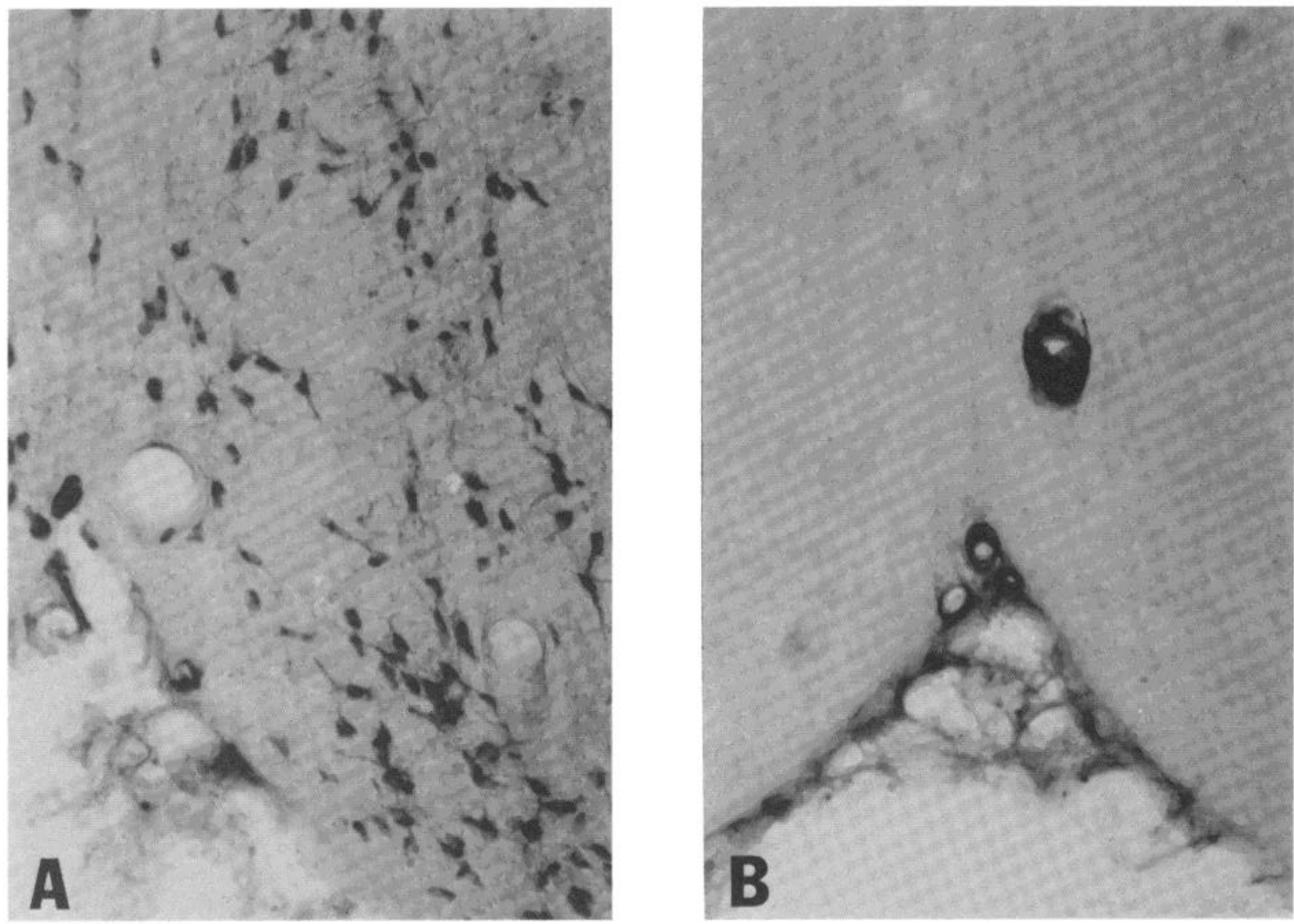

Figure 3. Immunocytochemical localization of either $(A)$ choline acetyltransferase using rat monoclonal antibody AB8 or (B) control using rat IgG. A, Photomicrograph showing ChAT-labeled neurons in the nucleus of the diagonal band (Magnification $\times 120$ ). $B$, Photomicrograph showing similar region as in $A$ incubated with culture supernatants of Sp2/0 myeloma cells with rat IgG $(1 \mathrm{mg} / \mathrm{ml}$ added) $($ Magnification $\times 120)$. No labeled neurons were observed.

plasm and processes of many neurons (Fig. $3 A$ ). Background and nuclear staining were consistently low. We observed ChAT immunoreactivity in several structures known to be cholinergic, including all motor nuclei examined. Examples of staining of cranial nerve motor nuclei are shown in Figure $4(A$ and $E)$. Large ChATimmunoreactive neurons also were stained in the basal forebrain (Fig. $4 C$ ), neostriatum (Fig. $4 B$ ), and medial septal nucleus (Fig. $4 D$ ).

\section{Discussion}

Although acetylcholine was the first identified neurotransmitter, the precise localization of cholinergic neurons in the central nervous system has remained unknown. Attempts to map the cholinergic system immunohistochemically, using polyclonal antisera to choline acetyltransferase, have been unreliable because of the questionable specificity of the antisera (Rossier, 1975, 1981). Since the hybridoma technique allows for the production of highly specific monoclonal antibodies against even impure immunogens, we have used this method to produce a panel of monoclonal antibodies to bovine ChAT. The monoclonal antibodies were screened for their capacity to bind active ChAT using a specfic double antibody co-precipitation assay (Levey et al., 1981). This assay was chosen because it measures directly the only reliable marker of ChAT, its enzymatic activity.
Alternatively, it might have been feasible to employ an assay measuring inhibition of enzyme by antibody. Previous assays with immune rat antisera failed to detect the presence of any antibody populations capable of inactivating ChAT.

The hybridomas were derived from a rat immunized with a relatively crude preparation of ChAT $(0.20 \mu \mathrm{mol} /$ $\mathrm{min} / \mathrm{mg}$ ), only about $0.1 \%$ pure. It may seem surprising, therefore, that the fusion resulted in $9 \%$ of the wells being positive for anti-ChAT antibodies. However, each well contained approximately 270,000 rat spleen cells, and thus the frequency of anti-ChAT antibody secreting spleen cells theoretically could be as low as $0.00003 \%$.

The co-precipitation assay was used to determine the cross-species reactivities of the antibodies to ChAT, as shown in Table I. Including the hybridomas produced by the present fusion, we now have a panel of monoclonal antibodies that exhibit three general patterns of crossspecies reactivities. One group reacts mainly to bovine ChAT (AB1 and AB4) (Levey and Wainer, 1982); a second group (AB5, AB6, AB7, and AB9) reacts with bovine, human, sheep, and cat enzyme; and a third pattern (AB8) shows binding to ChAT from all mammals tested. These three patterns of reactivities probably correspond to at least three different epitopes, or antigenic determinants, on ChAT that are recognized by the antibodies. These immunological data also suggest that there 
may be significant structural differences between the enzymes.

It is important to determine rigorously the specificity of any antibody to be used for immunohistochemistry. Although monoclonal antibodies are highly specific reagents, it is possible that they will bind to molecules other than the one of interest if these other molecules contain shared antigenic determinants. We employed the Western blotting technique to evaluate further the specificity of the monoclonal antibodies. This technique is superior to other methods for characterizing antibodyantigen interactions, such as double diffusion studies in Ouchterlony gels, because it is more sensitive, it is not dependent on precipitating antibodies, and it permits much finer resolution since a complex mixture of proteins
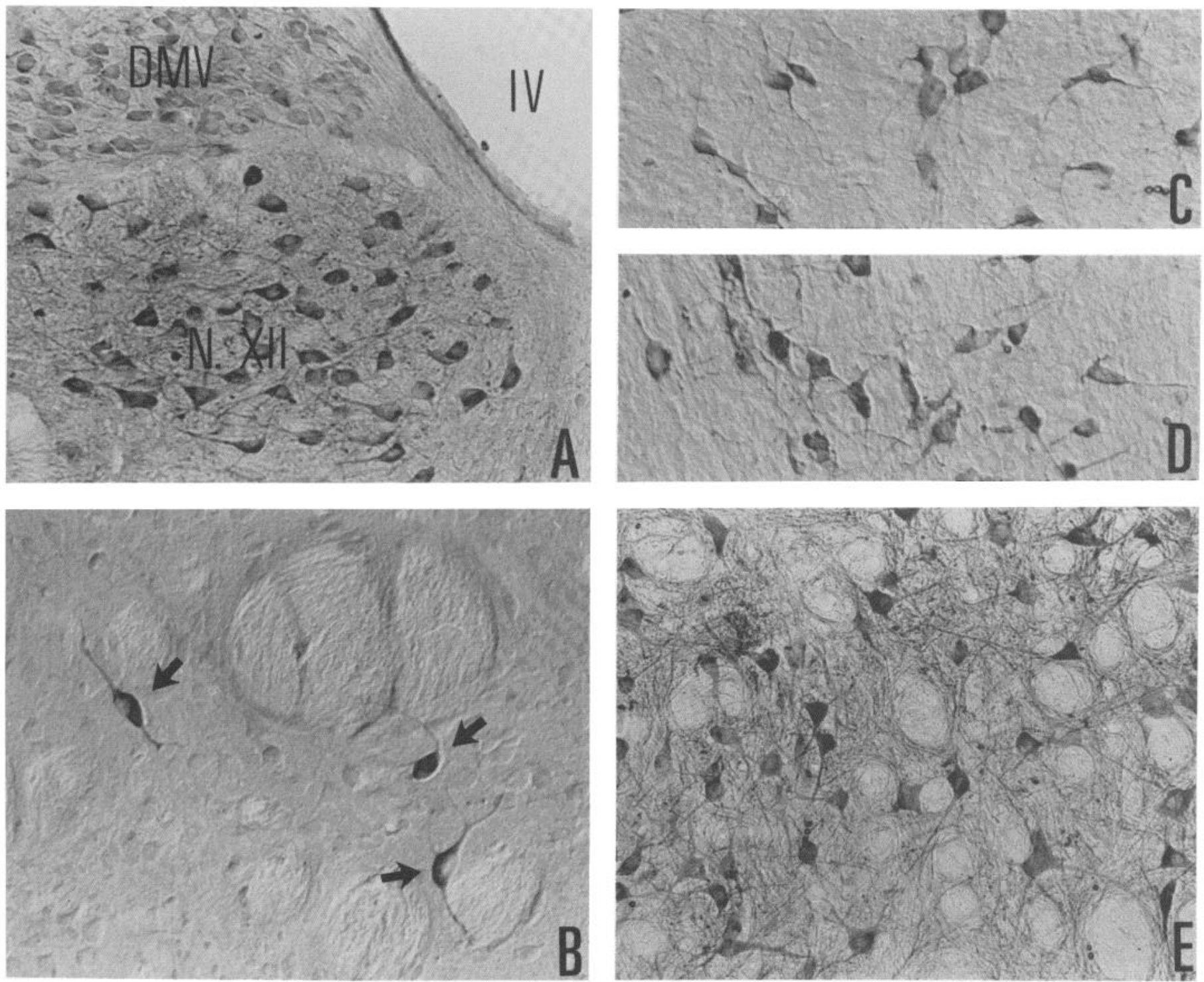

Figure 4. Light microscopic immunocytochemical localization of choline acetyltransferase in various regions of the rat brain. $A$, Photomicrograph showing ChAT-labeled neurons in the hypoglossal nucleus $(N$. XII) adjacent to the fourth ventricle $(I V)$. Lightly labeled neurons are also present in the dorsal motor nucleus of the vagus $(D M V)$ (Magnification $\times 160)$. B, Localization of ChAT within three neurons (arrows) in the neostriatum (Magnification $\times 320$ ). C, ChAT-labeled neuronal perikarya and processes in the ventromedial aspect of the globus pallidus (Magnification $\times 230$ ). $D$, Cholinergic cells in the medial septal nucleus. (Magnification $\times 230$ ). $E$, Numerous neurons showing ChAT immunoreactivity within the motor nucleus of the facial nerve (Magnification $\times 160)$. 
Western blotting. This is not surprising since ChAT protein is present in only trace amounts. These findings support the contention that, theoretically, it should not be possible to develop precipitin bands between crude brain extracts and anti-ChAT antisera (Rossier, 1975, 1981; Eckenstein et al., 1981).

Since not all large proteins (over 100,000 daltons) were transferred efficiently from the gels to the nitrocellulose blots, the possibility that higher molecular weight proteins were cross-reaclive with ChAT cannot be ruled out completely by Western blotting studies. However, another approach for characterizing the specificity of antigen binding which is independent of molecular weight considerations is immunoaffinity purification of ChAT. When one of the monoclonal antibodies was immobilized onto sepharose beads, active ChAT was eluted and resolved as two highly purified protein bands on SDSPAGE which appeared identical to the proteins resolved on the Western blots in the present study (Levey et al., 1982). These results suggest that the panel of antibodies reacts with antigenic determinants that are unique to the two 68,000 - to 70,000 -dalton proteins.

The monoclonal antibodies bind specifically to two closely related bovine proteins. The antibodies also react specifically with two human proteins of similar molecular weights using the Western blotting system (Levey et al., 1982). It is highly probable that either one or both of these proteins is ChAT because all of the antibodies bind specifically to active enzyme. The observation that at least three epitopes are shared by these proteins makes it more likely that they are both ChAT. In the studies of Cozzari and Hartman (1980), highly purified bovine ChAT consisted of two immunologically related proteins which exhibited molecular weights similar to the proteins found in the present studies. In addition, both proteins were enzymatically active. Ryan and McClure (1980) also observed two active forms of bovine ChAT that had molecular weights of 67,000 and 69,000 as determined by gel filtration. The two proteins resolved on the Western blot might be the same as the two bovine ChAT proteins studied by these other investigators; however, they will require further evaluation with respect to enzyme activity, structure analysis, and their physiologic significance.

Monoclonal antibody AB8 was used immunohistochemically to localize known cholinergic structures in the rat brain. The staining was performed on fixed, Vibratome-sectioned tissues using the free-floating peroxidaseantiperoxidase (PAP) method (Sternberger, 1979). Motor neurons (including anterior horn cells in the spinal cord and cranial nerve motor nuclei) have long been known to be cholinergic. We observed ChAT immunoreactivity in all motor nuclei examined, and examples are shown in Figure $4(A$ and $E)$. There has been recent interest in the source of cholinergic afferents to the cortex, because of the marked loss of cortical ChAT activity in certain types of dementia (Davies and Maloney, 1976). Some studies suggested that a major cortical cholinergic input arises from large AChE-positive cells in the basal forebrain of the rat (Shute and Lewis, 1967; Lehman and Fibiger, 1979; Wenk et al., 1980). These cells may, in fact, belong to a network of magnocellular basal forebrain neurons corresponding to the nucleus basalis of Meynert.
As shown in Figure $4 C$, large intensely stained cells were found in the ventro-medial aspect of the globus pallidus. Future studies should confirm whether these cells are the same as the AChE-positive cells which project to cortical areas.

A well studied central cholinergic pathway is the septohippocampal tract, and as expected, we observed ChATpositive cells in the medial septal nucleus (Fig. 4D). Another cholinergic system was stained in the neostriatum (Fig. 4B). Although the neostriatum has one of the highest specific activities of ChAT in the brain, we found that only a relatively small percentage of the neurons are cholinergic. This is consistent with others' observations of AChE-stained cells (Lehman and Fibiger, 1979). Since these neostriatal cholinergic cells are thought to be interneurons, the findings are also consistent with the recent observation that the majority of neostriatal neurons are projection cells (Preston et al., 1980).

In summary, we have developed a panel of monoclonal antibodies which will be valuable for immunochemical and immunohistochemical studies of cholinergic neurons. The monoclonal antibodies have been shown to be specific for ChAT by three independent methods: (i) the antibodies bound active enzyme in a double antibody precipitation assay; ( $i i)$ the antibodies bound specifically to two closely related proteins using the Western blotting technique; and (iii) one antibody, AB8, localized known cholinergic neurons. These antibodies have proven to be reliable reagents for immunohistochemistry in three different laboratories (A. Levey, D. M. Armstrong, and personal communication from $R$. Elde, the University of Minnesota). It will be extremely important to confirm mapping studies employing polyclonal antisera, because major discrepancies still exist. For example, staining of cells in the neocortex and in the habenula has been described as cholinergic in some studies (McGeer et al., 1979) and cholinoceptive in others (Kimura et al., 1981). Future applications of monoclonal anti-ChAT antibodies will include detailed mapping of cholinergic pathways in animal models and potentially in human tissues as well.

\section{References}

Aquilonius, S. M., S. A. Eckernas, and A. Sundwall (1975) Regional distribution of choline acetyltransferase in the human brain: Changes in Huntington's Chorea. J. Neurol. Neurosurg. Psychiatry 38: 669-677.

Burnette, W. N. (1981) "Western Blotting": Electrophoretic transfer of proteins from sodium dodecylsulfate-polyacrylamide gels to unmodified nitrocellulose and radiographic detection with antibody and radioiodinated protein A. Anal. Biochem. 112: 195-203.

Cozzari, C., and B. K. Hartman (1980) Preparation of antibodies specific to choline acetyltransferase from bovine caudate nucleus and immunohistochemical localization of the enzyme. Proc. Natl. Acad. Sci. U.S.A. 77: 7453-7457.

Davies, P., and A. J. F. Maloney (1976) Selective loss of central cholinergic neurons in Alzheimer's disease. Lancet 2: 1403.

Drachman, D. A. (1981) The cholinergic system, memory, and aging. In Brain Neurotransmitters and Receptors in Aging and Age-Related Diseases. Vol. 17: Aging, S. J. Enna, T. Samorajski, and B. Beer, eds., pp. 255-268, Raven Press, New York.

Eckenstein, F., Y. -A. Barde, and H. Thoenen (1981) Production 
of specific antibodies to choline acetyltransferase purified from pig brain. Neuroscience 24: 993-1000.

Fonnum, F. (1975) A rapid radiochemical method for the determination of choline acetyltransferase. J. Neurochem. 24: 407-409.

Kan, K. -S., L. -P. Chao, and L. S. Forno (1980) Immunohistochemical localization of choline acetyltransferase in the human cerebellum. Brain Res. 193: 165-171.

Kimura, H., P. L. McGeer, J. H. Peng, and E. G. McGeer (1981) The central cholinergic system studied by choline acetyltransferase immunohistochemistry in the cat. J. Comp. Neurol. 200: 151-201.

Laemmli, U. K. (1970) Cleavage of structural proteins during the assembly of the head of bacteriophage $\mathrm{T}_{4}$. Nature 227: $680-685$.

Lehman, J., and H. C. Fibiger (1979) Mini review: Acetylcholinesterase and the cholinergic neuron. Life Sci. 25: 1939-1947.

Levey, A. I., and B. H. Wainer (1982) Cross-species and intraspecies reactivities of monoclonal antibodies against choline acetyltransferase. Brain Res. 234: 469-473.

Levey, A. I., M. Aoki, F. W. Fitch, and B. H. Wainer (1981) The production of monoclonal antibodies reactive with bovine choline acetyltransferase. Brain Res. 218: 383-387.

Levey, A. I., D. B. Rye, and B. H. Wainer (1982) Immunochemical studies of bovine and human choline-o-acetyltransferase. $\mathrm{J}$. Neurochem., in press.

McGeer, E. G., P. L. McGeer, T. Hattori, and V. K. Singh (1979) Immunohistochemistry of choline acetyltransferase. Prog. Brain Res. 49: 59-70.

McKearn, T. J. (1980) Fusion of cells in an adherent monolayer. In Monoclonal Antibodies, R. H. Kennett, T. J.
McKearn, and K. B. Bechtol, eds., p. 368, Plenum Press, New York.

Merril, C. R., D. Goldman, S. A. Sedman, and M. H. Ebert (1981) Ultrasensitive stain for proteins in polyacrylamide gels shows regional variation in cerebrospinal fluid proteins. Science 211: 1437-1438.

Preston, R. J., G. A. Bishop, and S. T. Kitai (1980) Medium spiny neuron projection from the rat striatum: An intracellular horseradish peroxidase study. Brain Res. 183: 253-263.

Rossier, J. (1975) Immunohistochemical localization of choline acetyltransferase: Real or artifact? Brain Res. 98: 619-622.

Rossier, J. (1981) Serum monospecificity: A prerequisite for reliable immunohistochemical localization of neuronal markers including choline acetyltransferase. Neuroscience 6 : 989-991.

Ryan, R. J., and W. O. McClure (1979) Purification of choline acetyltransferase from rat and cow brain. Biochemistry 18: 5357-5365.

Ryan, R., and W. O. McClure (1980) Physical and kinetic properties of choline acetyltransferase from rat and bovine brain. J. Neurochem. 34(2): 395-403.

Shute, C. C. D., and P. R. Lewis (1967) The ascending cholinergic reticular system: Neocortical, olfactory, and subcortical projections. Brain 90: 497-519.

Sternberger, L. A. (1979) Immunocytochemistry, Ed. 2, pp. 104-169, John Wiley and Sons, New York.

Terry, R. D., and P. Davies (1980) Dementia of the Alzheimer type. Annu. Rev. Neurosci. 3: 77-95.

Wenk, H., V. Bigl, and U. Meyer (1980) Cholinergic projections from magnocellular nuclei of the basal forebrain to cortical areas in rats. Brain Res. Rev. 2: 295-316. 